\title{
LXXIII. Experiments tending to prove that the prism has a calorific focus, and that Dr. Herschel was mistaken in supposing he separated the heat and light of the solar rays
}

Joseph Reade M.D.

To cite this article: Joseph Reade M.D. (1815) LXXIII. Experiments tending to prove that the prism has a calorific focus, and that Dr. Herschel was mistaken in supposing he separated the heat and light of the solar rays, Philosophical Magazine Series 1, 45:206, 422-424, DOI: 10.1080/14786441508638464

To link to this article: http://dx.doi.org/10.1080/14786441508638464

央 Published online: 27 Jul 2009.

Submit your article to this journal ¿

山 Article views: 3

Q View related articles ¿ 
ble* or stone: and that frits, or unaiterable metallic combinations, have not been the only pigments employed by great artists; and that their varnishes have not been sought for amongst the transparent combinations of the earths with water, or amongst the crystalline transparent compounds unalterable in the atmosphere + .

Rome, January 14, 1815.

LXXIII. Experiments tending to prove that the Prism has a calorific Focus, and that Dr. Herschel was mistaken in supposing he separated the Heat and Light of the Solar Rays. By Joseph Reade, M.D.

\section{To Mr. Tilloch.}

SIR,- $\mathrm{H}_{\mathrm{AVING}}$ fixed a piece of pasteboard in the frame of a dressing-glass, in which $I$ cut an opening or slit a little larger than the bulb of a thermometer, and of a sufficient length to let the whole extent of one of the prismatic colours pass through; and having placed a very sensible mercurial thermometer on an inclined plane of wood covered with white paper,-I placed this plane behind the dressing frame sustaining the pasteboard on a table: I now set a prism moveable on its axis in the upper part of an open window at right angles to the solar ray, and turned it about till its refracted coloured spectrum became stationary on the table placed at a proper distance from the window. The experiment was so regulated as to let the rays of one colour pass through the opening in the pasteboard and fall on the thermometer, which when placed in the shade behind the screen stood at $50^{\circ}$.

Exp. 1.-Having arranged the thermometer, and allowed the red, or more correctly speaking the orange rays to fall on the bulb; in five minutes it rose from 50 to 58 , or eight degrees.

Exp. 2.-I lowered my thermometer to $50^{\circ}$, by plungeing it in some dry sand at that temperature, and then replaced it on the inclined plane : on bringing the green rays of the spectrum through the opening, so as to immerse the entire thermometer

\footnotetext{
* Copper, it is evident, from the specimeus in the ruins of Pompeii, is a very perishable material, and therefore, even enamels made on copper will yield to time. Canvass, by being impregnated with bitumen, is rendered much more durable, as is evident from the duration of the linen impregnated with bitumen and asphaltum used for infolding the Egyptian mummies.

† The artificial hydrat of alumina will probably be found to be a substance of this kind: possibly the solution of boracic acid in alcohol will form a varnish.-The solution of sulphur in alcohol is likewise worthy of an experiment. Many other similar combinations might be named.
} 
as in the former experiment, it rose from 50 to 54, or gained four degrees.

Exp. 3.-Having again reduced my thermometer to $50^{\circ}, 1$ placed it on the inclined plane; and having allowed the violet rays to fall on it, the rise was from 50 to $5 \mathrm{l}$, or one degree.

So far these experiments, assimilated as much as occasion required to Dr.Herschel's, would seem to confirm the inferences drawn by that celebrated astronomer. However, so early as the year 1802, when at Edinburgh College attending Dr. Hope's interesting and scientific lectures on chemistry, I was led to doubt the conclusions drawn from these experiments, but at that early period did not venture to oppose such high authority.

Exp.4.-Having finished the former experiments, l-retnoved the pasteboard screen, and in its place interposed a sheet of white paper on which the spectrum was received; it was gradually approximated to within one inch of the prism, where it was properly fastened on a stand. The spectrum at this distance was one-fourth of an inch in breadth, bounded on the one side by. orange and yellow rays, and on the other by blue and violet, while light occupied the middle; this white light was much more powerful and luminous than the surrounding sun-beams. Indeed, it appeared exactly like the light concentrated in the focus of a burning-glass, which made me strmgly suspect that it was likewise more calorific. Nor was I mistaken; for, on placing the thermometer in those rays, it rose in ten minutes to $81^{\circ}$; the heat of the neighbouring sun-shine being only $70^{\prime}$. The thermometer rose and fell alternately as it was removed in and out of the spectrum. From this experiment we must infer that Dr. Herschel made his experiments not only on the heat of the solar ray, but likewise on the heat accumulated by the converging power of the prism. Indeed, it appears rather singular that the action of this well-known instrument should heretofore have been so superficially investigated. Every glass wedge must produce a focal heat, for those rays in the vicinity of the angle nust suffer a more powerful refraction than the others; consequently at a given distance the heat and light must be condensed. Let us suppose the vertical section of a triangular glass wedge or prism, resting on its base, to be represented in the following diagram:

$A B$, two rays of light, coming from the sun $\mathrm{S}$, strike on the prism $C D E$. The ray $B$ near the base is but slightly refracted, whilst on $\mathrm{K}$ the other hand the

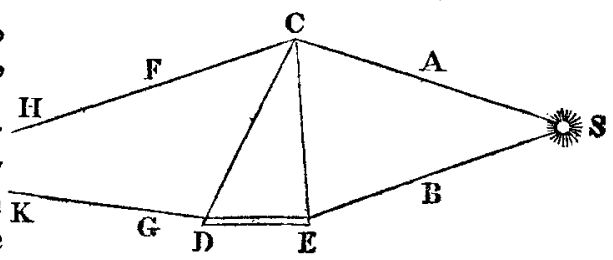
ray $A$ coming through the upper refracting angle is considerably D d 4

bent 
bent towards a perpendicular. The letters HK repregent the prismatic focus: for as the quantity of heat and light contained in the space $\mathrm{FG}$ is by the refracting power of the prism conveyed into the smaller suace $\mathrm{HK}$; consequently HK must be more luminous and calorific than FG. In my next paper I shall endeavour to show why the red rays are more calorific than the green or violet, \&c.

Exp. 5.-June 23, 1814, at half past two in the afternoon, the sun shining through an open wiudow fronting the west, I placed a highly sensible and correct thermometer (made by $\mathrm{Mr}$. Bath of the Cork Institution) on a sheet of white paper, resting horizontally on a writing-table. In five minutes it rose in the full sun-beams to $82 \frac{\mathrm{I}}{2}$; and after remaining for some time stationary, I held a large prism at about one inch distance inmediately over it, and in such a marner as to convey the rays of light as much as possible to the prismatic focus, and also to immerse the enire thermometric bulb and cylinder in a spectrum of transmitted light. 1 need scarcely again remark that this spectrum was composed of medion white light, bounded on the one side by orange and yellow, and on the other by blue and violet. In five minutes the thermometer rose to 101 ; or, in other words, the transmitted light was heated $18 \frac{1}{2}^{\circ}$ above the full sunshine by passing through the prism. On removing the prism the thermometer fell in five minutes to $85^{\circ}$; and on again immersing it in the spectric light it rose to $101^{\circ}$. About half past three I ended these experiments, simple in their manipulation, and obvious in their inferences.

Cork, May 4, 1815.

Sir, I beg leave to remain

Your obedient servant, Joseph Reade, M.D.

\section{New Outlines of Chemical Philosophy. By Ez. WALKer, Esq. of Lynn, Norfolk.}

[Continued from p. 21.]

From the discordant opinions which prevail among the writers on electricity, it appears that this branch of physics is still very. far from being clearly understood. It has been generally supposed, that where no spark is elicited, no permanent effect is produced upon an insulated conducting body.

But the truth is, that most of the operations of nature, in which electricity is concerned, are produced by inducted electricity; and consequently, the effects of those elements on matter become an interesting subject of philosophical discussion.

In order to investigate the laws of electrical phænomena, with 